\title{
Cleopus japonicus: releases and distribution of the buddleia biological control agent in New Zealand
}

\author{
M.C. Watson, T.M. Withers and M. Heaphy \\ Scion, Private Bag 3020, Rotorua 3046, New Zealand \\ Corresponding author: Michelle.Watson@scionresearch.com
}

\begin{abstract}
The buddleia leaf weevil, Cleopus japonicus, was released in New Zealand by Scion in 2006 as a biological control agent for the weed Buddleja davidii. One thousand C. japonicus adults were released at each of five commercial forest sites in the North Island. A further 33 releases of approximately 14,910 C. japonicus were made between 2006 and 2011 in the North and South Islands, on both privately- and publically-owned land and sites of conservation importance. The weevil is known to have established at all sites, with the possible exception of one release made in 2007. Location data of $C$. japonicus provided by local and regional councils, DOC, forest health officers and others have provided information on the spread of C. japonicus. These data show C. japonicus has spread over $50 \mathrm{~km}$ from some release sites and is rapidly increasing in population density and distribution.
\end{abstract}

Keywords buddleia leaf weevil, Cleopus japonicus, Buddleja davidii, dispersal, distribution maps.

\section{INTRODUCTION}

The buddleia leaf weevil, Cleopus japonicus Wingelmüller was first released in New Zealand as a biological control agent for the weed buddleia (Buddleja davidii Franchet) in October 2006 (Gresham et al. 2009). Buddleja davidii is an invasive weed in exotic and indigenous forests in New Zealand. It colonises disturbed sites, competing with tree crops and displacing native pioneer species. The weed is estimated to cost the forestry industry between $\$ 0.5$ and $\$ 2.9$ million annually in control costs and loss of production (Hill et al. 2003). In addition, councils, the Department of Conservation (DOC) and other land owners and managers incur ongoing expenses associated with managing it. Successful biological control of this weed may assist the forest industry to reduce the use of chemicals during the establishment phase of plantation forests.

Cleopus japonicus is native to central China. The larvae and adults feed on the surface of buddleia leaves and cause heavily damaged leaves to drop (Zhang et al. 1993). At the time of release there was no information about the ability of the weevil to disperse to colonise new sites, except that adult weevils are able to fly while larvae can move only short distances. Modelling of expected population dynamics of $C$. japonicus by Kriticos et al. (2009) predicted that population growth and resource consumption by the weevil would increase exponentially with time after release and that this would be greater at warmer sites than cooler sites. The model indicated that complete defoliation of B. davidii by C. japonicus would 
occur at some sites, which would then lead to migration. Four different scenarios were tested, as it was unknown how rapidly adults or larvae would respond to the reduction in suitable host plant foliage.

Since 2006, C. japonicus release and distribution records havebeen accurately retained. This paper will analyse the current distribution of C. japonicus and its recorded patterns of dispersal from known release sites in the four and a half years since its release. From now on stakeholders and members of the public are being encouraged to re-distribute the weevil themselves, so accurate analyses of dispersal patterns will no longer be possible.

\section{METHODS}

Following approval from the Environmental Risk Management Authority (ERMA) to release C. japonicus in New Zealand, five release sites were initially chosen in commercial forests in the central North Island to monitor the establishment, spread and effects of the weevil under a range of climates (Figure 1) (Kriticos et al. 2009). At each site 1000 weevils were released over a 4-month period and the sites were monitored closely for 3 years. Once establishment was confirmed at all five sites, focus then turned to establishing C. japonicus more widely in New Zealand. Regional Councils (RC), District Councils (DC), forestry companies and DOC were given the opportunity to make releases of the weevil in suitable habitats that they managed, and together these releases totalled at least 14,910 individuals. Adults released in 2006-2007 were reared in the Scion laboratory; from 2008 all releases were of field-collected adults. Most field collections were made from the Scion nursery site, Kinleith, Whakarewarewa and Rawhiti Forests. Areas where B. davidii was a particular problem were targeted, but the majority of releases to date have been within the central North Island. Most release sites were revisited at least yearly and the presence of C. japonicus adults, larvae and feeding recorded. This involved a thorough search of the $B$. davidii in areas where the release was made (ranging from $15 \mathrm{~min}$ to $1 \mathrm{~h}$ ). Site visits were carried out by those who made the original release. A visual estimation of the percentage of foliage removed by C. japonicus was made by comparing affected plants with those with no damage. Establishment of C. japonicus was declared at a site when the agent was present 1 year after release.

The resultant distribution reported here is an amalgamation of positive C. japonicus identification records collected by Scion during surveys, as well as random finds by Scion staff and contacts within the forestry industry, pest surveillance officers, council staff and members of the public. Not all of the numerous releases made within commercial forest estates in the past 2 years are reported here as these have not been revisited to ascertain resultant C. japonicus dispersal.

\section{RESULTS}

As reported previously (Watson et al. 2009), C. japonicus established successfully at all release sites (Table 1), with the possible exception of one of the 2007 Upper Hutt release sites. The establishment of releases made less than a year ago has yet to be ascertained. Assuming that all new location records to date are a result of natural C. japonicus dispersal, the agent has dispersed between 5-50 km from each of the initial 2006 release sites in the intervening 4.5 years. Feeding damage by the weevil has been considerable, with complete defoliation of some plants.

Cleopus japonicus has now been released in many areas of the North Island and several sites on the South Island (Figure 1). The current distribution of C. japonicus in New Zealand is shown in Figure 2. According to observations made by land managers, dispersal from smaller releases made from 2007 onwards (250 to 500 adult weevils) was less than $10 \mathrm{~m}$ at all sites in the first year, ranged from 5 to $20 \mathrm{~m}$ in the second, $10 \mathrm{~m}$ to $1 \mathrm{~km}$ in the third, and from $10 \mathrm{~m}$ to $2 \mathrm{~km}$ in the fourth year. The most rapid dispersal from the releases made since 2007, was recorded at the Kaikoura site where the agent had spread approximately $2 \mathrm{~km}$ from the release plants at year 4 . 
Table 1 Cleopus japonicus release sites as at April 2011. Sites marked with ${ }^{\star}$ are experimental sites. $\mathrm{RC}=$ Regional Council, DC $=$ District Council. Codes in brackets are Crosby regions (Crosby et al. 1976). Where more than one release was made in the same area on the same day, this is shown as ( $\times$ number of release sites). $\wedge=$ many releases made at the same site over many months to give the total release number. \#=many releases made at nearby sites, over a number of years. NOTE: C. japonicus has been located at one of the two Upper Hutt sites.

\begin{tabular}{|c|c|c|c|c|}
\hline Who made release & Location & Date released & $\begin{array}{c}\text { Number } \\
\text { adults }\end{array}$ & $\begin{array}{c}\text { Present after } \\
1 \text { year }\end{array}$ \\
\hline Scion & Whakarewarewa Forest & Sep 2006 & 200 & Yes \\
\hline Scion & Whakarewarewa Forest* & Oct $2010^{\wedge}$ & 1000 & Yes \\
\hline Scion & Kinleith Forest*(TO) & Oct $2010^{\wedge}$ & 1000 & Yes \\
\hline Scion & Esk Forest $^{*}(\mathrm{HB})$ & Oct $2010^{\wedge}$ & 1000 & Yes \\
\hline Scion & Rawhiti Forest* (BP) & Oct $2010^{\wedge}$ & 1000 & Yes \\
\hline Scion & Taupo Forest* (TO) & Oct $2010^{\wedge}$ & 1000 & Yes \\
\hline Scion & Scion grounds* $(\mathrm{BP})$ & 2007-2011\# & 4850 & Yes \\
\hline Greater Wellington RC & Upper Hutt (WN) & Nov 2007 & $250(\times 2)$ & Yes \\
\hline Horizons RC & Taumarunui (TO) & Nov 2007 & $250(\times 2)$ & Yes \\
\hline Scion & Murupara (TO) & Dec 2007 & 500 & Yes \\
\hline PF Olsen & Pyes Pa Rd (BP) & Feb 2008 & $250(\times 4)$ & Yes \\
\hline Environment BoP RC & Tauranga (BP) & Feb 2008 & 500 & Yes \\
\hline Environment Canterbury & Kaikoura (KA) & Mar 2008 & 500 & Yes \\
\hline Tasman DC & Bishopdale,Riwaka (NN) & Apr 2008 & $250(\times 2)$ & Yes \\
\hline Northland RC & Kaikohe (ND) & Apr 2008 & 500 & Yes \\
\hline Scion & Kaingaroa Forest ${ }^{\star}(\mathrm{BP})$ & Nov $2008 \wedge$ & 1000 & Yes \\
\hline Scion & Kinleith Forest* (TO) & Nov $2008 \wedge$ & 1000 & Yes \\
\hline Scion & Tauranga (BP) & Mar 2009 & 60 & Yes \\
\hline Juken Nissho & Patunamu Forest & Apr 2009 & 200 & Yes \\
\hline Environment BoP RC & Lake Rotoma (BP) & May 2009 & 300 & Yes \\
\hline Environment BoP RC & Te Urewera (NP) & May 2009 & 500 & Yes \\
\hline Hawke’s Bay RC & Puketapu (HB) & May 2009 & 300 & Yes \\
\hline Rayonier & Matariki Forests (BP) & May 2009 & 300 & Yes \\
\hline Greater Wellington RC & Masterton (WA) & Apr 2010 & 300 & - \\
\hline Scion & Rotorua (BP) & Apr 2010 & $100(\times 3)$ & - \\
\hline Scion & Rotorua (BP) & Apr 2011 & 200 & - \\
\hline Juken Nissho & Gisborne (GB) & Apr 2011 & 400 & - \\
\hline PF Olsen & Nemona Forest (BR) & Apr 2011 & $100(\times 2)$ & - \\
\hline Newmont Waihi Gold & Waihi (CO) & Apr 2011 & 300 & - \\
\hline
\end{tabular}

\section{DISCUSSION}

Cleopus japonicus has successfully established at a range of sites in New Zealand from releases of 60 to 500. It is not known why C. japonicus has not been relocated at one of the Upper Hutt sites. The weevil may be present at this site at very low numbers, or may have moved to another area, or may not have established at this site as it proved unsuitable for some reason.
The rate of C. japonicus population dispersal appears to be increasing many-fold faster with each subsequent year since the first release, presumably as each population increases exponentially in density. At first, C. japonicus dispersal was relatively slow. At the first five release sites made in 2006-2007 the weevil was calculated to have dispersed on average between 27 and $65 \mathrm{~m} /$ year (Watson et al. 2011). At the coastal 


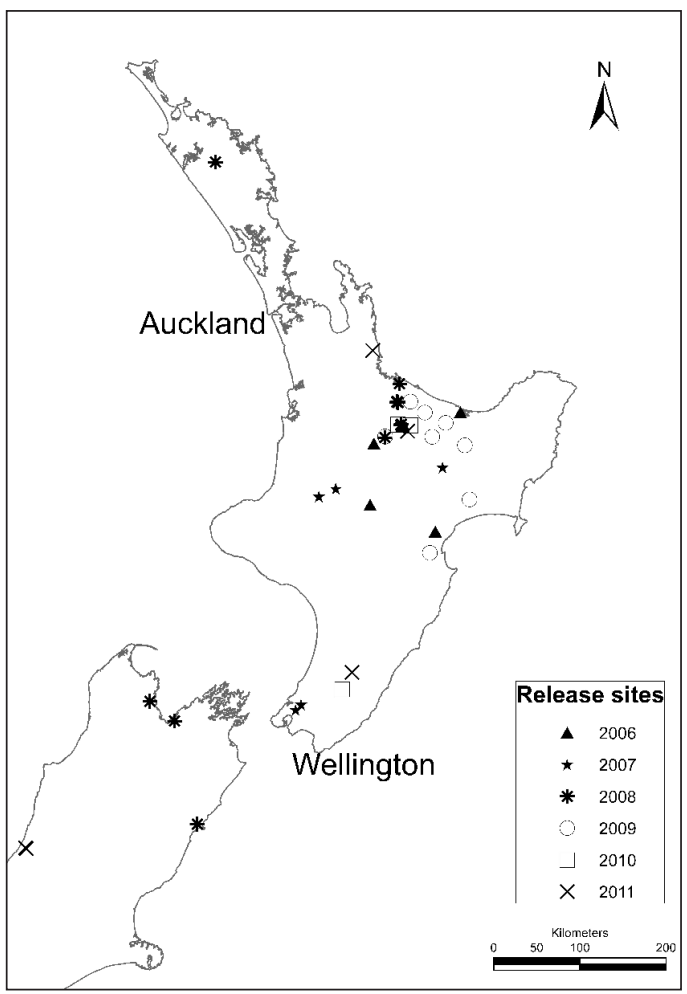

Figure 1 Cleopus japonicus release sites within New Zealand distinguished by year (2006-2011).

release site near Ohope, which is the warmest of these sites, C. japonicus has been particularly successful at colonising sites of previously undamaged B. davidii. Here Cleopus japonicus was found up to $1 \mathrm{~km}$ away by the third year and is now at least $50 \mathrm{~km}$ from the initial release site (Figure 2 ). This is consistent with predictions made by Kriticos et al. (2009). At the Whakarewarewa release site in Rotorua, the average spread was 27 $\mathrm{m}$ in the first 3 years, but is now present up to 40 $\mathrm{km}$ away (Figure 2). At the Kinleith and Esk forest release sites the dispersal is now at least $30 \mathrm{~km}$. More recent releases have shown lower rates of initial dispersal, in keeping with their earlier stages of population growth and spread.

As was predicted by the population modelling (Kriticos et al. 2009) feeding damage by C. japonicus is strongly seasonal (Watson et al. 2011), with the greatest damage in late summer to autumn when most $B$. davidii plants, from

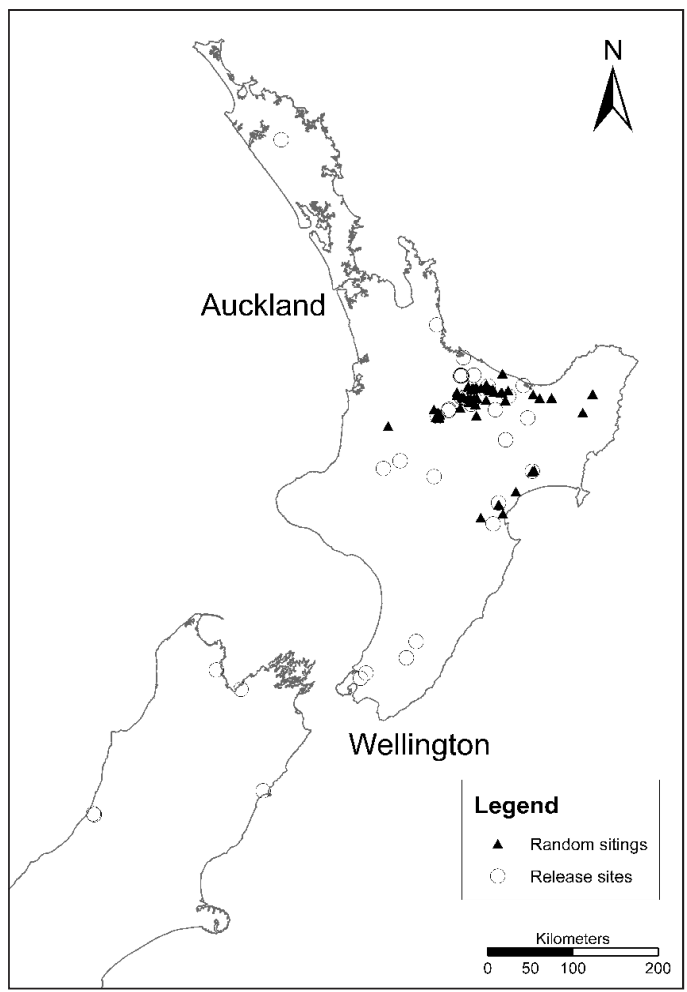

Figure 2 Distribution of Cleopus japonicus in central North Island at April 2011.

seedlings to very large bushes, become completely defoliated. This peak is a result of a dramatic increase in the number of larvae present at this time. Modelling by Watt et al. (2007) indicated that greater than $30 \%$ defoliation to $B$. davidii was required to reduce plant height growth as B. davidii can strongly compensate for defoliation. A field trial demonstrated that C. japonicus has the ability to suppress the growth of $B$. davidii, with a $19 \%$ reduction in plant height in un-treated compared with insecticide treated plants 463 days after trial initiation (Watson et al. 2010). The weevil has been observed by M. Watson and T. Withers in April and May flying in large numbers to locate suitable new hosts when local resources are exhausted. It has successfully located isolated plants, including tiny seedlings, and colonised new areas. Recent observations of complete defoliation of B. davidii bushes within $1 \mathrm{~km}$ of several of the original release 
sites in the past two to three seasons suggests that growth suppression of $B$. davidii is likely.

The current distribution of $C$. japonicus in New Zealand is patchy, but it is hoped the agent will eventually establish in every site where $B$. davidii is present. In much of the South Island $B$. davidii is not as serious a weed as in the North Island, with the exception of some dense infestations on the South Island's north and east coasts. Similarly, this weed is only patchily distributed in Northland and the west coast of the North Island. Yet, Kriticos et al. (2005) predicted that all of New Zealand is climatically suitable for $B$. davidii other than the higher altitude mountainous areas, so it poses a potential threat to all disturbed habitats over much wider areas than its current distribution reveals. The weevil appears to be well suited to the New Zealand climate, with the greatest effect on buddleia seen at the warmer sites (Watson et al. 2011).

Land owners and managers involved with the original sites have been redistributing adult C. japonicus to other areas with $B$. davidii from late spring to autumn. This redistribution will further increase the spread of $C$. japonicus and bring the environmental benefits of this biological control agent to regions throughout New Zealand.

\section{ACKNOWLEDGEMENTS}

I would like to thank the many staff at Scion who assisted in rearing, distributing and monitoring the weevil. In particular: Belinda Gresham, Pam Taylor, Andrea Sharpe, Dave Hayes, Katrin Walbert, Judy Gardner and Carol Rolando. In addition, the summer students Rachel Hood, Mitchell West, Anneke Herman and Sam Brown all contributed greatly to this project. This work would not have been possible without the support and assistance of the many forestry companies, regional and district councils and the public for their support and keeping us up-todate with new $C$. japonicus locations.

\section{REFERENCES}

Crosby TK, Dugdale JS Watt JC 1976. Recording specimen localities in New Zealand: an arbitrary system of areas and codes defined. New Zealand Journal of Zoology 3: 69.
Gresham BA, Watson MC, Withers TM 2009. A laboratory rearing method for Cleopus japonicus (Wingelmüller) (Coleoptera: Curculionidae) a biological control agent for Buddleja davidii Franchet (Lamiales: Scrophulariaceae) in New Zealand. New Zealand Entomologist 32: 55-58.

Hill RL, Withers TM, Kay MK, Richardson B, Kimberley MO 2003. Application to ERMA to release buddleia leaf weevil, Cleopus japonicus, from containment as a biological control agent for Buddleja davidii (NOR02001). Scion, Rotorua, New Zealand.

Kriticos D, Watt MS, Withers TM, Leriche A, Watson MC 2009. A process-based population dynamics model to explore target and non-target impacts of a biological control agent. Ecological Modelling 220: 2035-2050.

Watt MS, Whitehead D, Kriticos DJ, Gous SF, Richardson B 2007. Using a process-based model to analyse compensatory growth in response to defoliation: Simulating herbivory by a biological control agent. Biological Control 43: 119-129.

Watson MC, DJ K, Berndt LA. Withers TM 2009. Establishment and early spread of the buddleia leaf weevil. In: IUFRO International Forest Biosecurity Conference Popular Summaries, Rotorua. NZFRI Bulletin No. 233: 87-89.

Watson MC, Watt M, Withers TM 2010. Rate of dispersal a key success factor for weed biological control agents within forest plantations. In: Zydenbos SM ed. Proceedings of the 17th Australasian Weeds Conference. Christchurch, New Zealand Plant Protection. Pp. 364-367.

Watson MC, Watt MS, Withers TM, Kimberley MO, Rolando CA 2011. Potential for Cleopus japonicus to control the weed Buddleja davidii in plantation forests in New Zealand. Forest Ecology \& Management 261: 78-83.

Zhang X, Xi Y, Zhou W, Kay M 1993. Cleopus japonicus, a potential biocontrol agent for Buddleja davidii in New Zealand. New Zealand Journal of Forestry Science 23: $78-83$. 